LBNL-46981

PAPER REFERENCE NUMBER: C-VIII.3

\title{
Formation of ohmic contacts to MOCVD grown p-GaN by controlled activation of $\mathrm{Mg}$
}

\author{
E. Kamiñska ${ }^{* 1}$, A. Piotrowska ${ }^{1}$, A. Barcz ${ }^{1,2}$, D. Bour ${ }^{3}$, M. Zielinski ${ }^{2}$, \\ J. Jasinski ${ }^{4,5}$ \\ ${ }^{1}$ Institute of Electron Technology, Warsaw, Poland \\ ${ }^{2}$ Institute of Physics, PAS, Warsaw, Poland \\ ${ }^{3}$ Agilent Laboratories, Palo Alto, USA \\ ${ }^{4}$ Lawrence Berkeley Laboratory, Berkeley, CA, USA \\ ${ }^{5}$ Institute of Experimental Physics, Warsaw University, Poland
}

\begin{abstract}
We report on the formation of low resistivity ohmic contacts to $p-G a N, r_{c}<10^{-4} \Omega \mathrm{cm}^{2}$, by increasing the concentration of the active $\mathrm{Mg}$ in the subcontact zone, via $\mathrm{Zr}$-mediated release of hydrogen.

Keywords: ohmic contact, p-GaN, hydrogen, $\mathrm{ZrN}, \mathrm{ZrB}_{2}$.
\end{abstract}

\section{Introduction}

The development of procedures for the fabrication of ohmic contacts to $\mathrm{p}$ type $\mathrm{GaN}$ is one of the most stimulating goals in the technology of GaN-based devices. Recently, evidence was given that the subsurface region of MOCVD-grown $\mathrm{p}-\mathrm{GaN}$ contains a substantial amount of hydrogen, which due to the passivation of magnesium, seems to be responsible for the difficulties in making ohmic contacts. To resolve this problem we have used $\mathrm{Zr}$-based metallization and demonstrated its usefulness as a drain enabling the evolution of hydrogen from the semiconductor subcontact region under heat treatment [1]. This work presents a detailed study of the process of zirconium-mediated removal of hydrogen. We report the results of experiments designed to analyse the effect of temperature and gas ambient on the concentration profiles of hydrogen in the subcontact region of $\mathrm{p}-\mathrm{GaN}$ as well as on the electrical properties and the microstructure of contacts.

*Corresponding author: tel: +48 2254 87942; fax: +48 2284 70631; e-mail: eliana@ ite.waw.pl 


\section{Experimental procedure}

The GaN samples used in this study were grown by MOCVD on sapphire substrate with an undoped $\mathrm{GaN}$ buffer layer, followed by $1.5 \mu \mathrm{m}$ thick $\mathrm{p}-\mathrm{GaN}$ doped with $\mathrm{Mg}$. The experiments were performed on both as grown and post growth-activated material. After the activation of $\mathrm{Mg}$, the hole concentration was $1 \times 10^{18} \mathrm{~cm}^{-3}$. $\mathrm{Zr}$-based metallization, consisting of a $\mathrm{ZrN}(100 \mathrm{~nm}) / \mathrm{ZrB}_{2}(100 \mathrm{~nm})$ bilayer was deposited by sequential DC magnetron sputtering from $\mathrm{ZrN}$ and $\mathrm{ZrB}_{2}$ targets, respectively. Heat treatments were conducted in a RTP system at $750-1150^{\circ} \mathrm{C}$, for 30 s. in $\mathrm{N}_{2}$ flow. Compositional depth profiling was performed with secondary ion mass spectrometry (SIMS) using a Cameca $6 \mathrm{~F}$ instrument, with either cesium or oxygen as primary beam. The microstructure of $\mathrm{ZrN} / \mathrm{ZrB}_{2}$ metallization on $\mathrm{GaN}$ was investigated by cross-sectional transmission electron microscopy (XTEM) and selected area diffraction (SAED) analysis in JEOL 2000EX microscope. Contact resistivity was evaluated by circular TLM method.

\section{Results and discussion}

In order to understand the behaviour of hydrogen in $\mathrm{p}-\mathrm{GaN}$ under annealing, the first question to be addressed concerns the effect of the post growth annealing, routinely performed to activate $\mathrm{Mg}$ as acceptor dopant, on hydrogen concentration. Our results show that, despite of a significant change in the free barrier concentration, the annealing of bare $\mathrm{p}-\mathrm{GaN}$ at $800^{\circ} \mathrm{C}$ does not affect noticeably the amount and the distribution of hydrogen. The level of $\mathrm{H}$ remains stable upon annealing up to $800^{\circ} \mathrm{C}$ of $\mathrm{ZrN} / \mathrm{ZrB}_{2}$-capped semiconductor as well. Such a processing in $\mathrm{N}_{2}$ ambient, however, enables the desorption of hydrogen trapped during the sputter-deposition of $\mathrm{ZrB}_{2}$ and $\mathrm{ZrN}$ films, which was found to enhance the thermal stability of the contact. Fig.1 shows depth profiles of $\mathrm{H}$ and $\mathrm{Mg}$ in $\mathrm{p}-\mathrm{GaN}$ after annealing at temperatures $800^{\circ} \mathrm{C}-1100^{\circ} \mathrm{C}$ in $\mathrm{N}_{2}$, and at $800^{\circ} \mathrm{C}$ in $\mathrm{O}_{2}$ ambient.
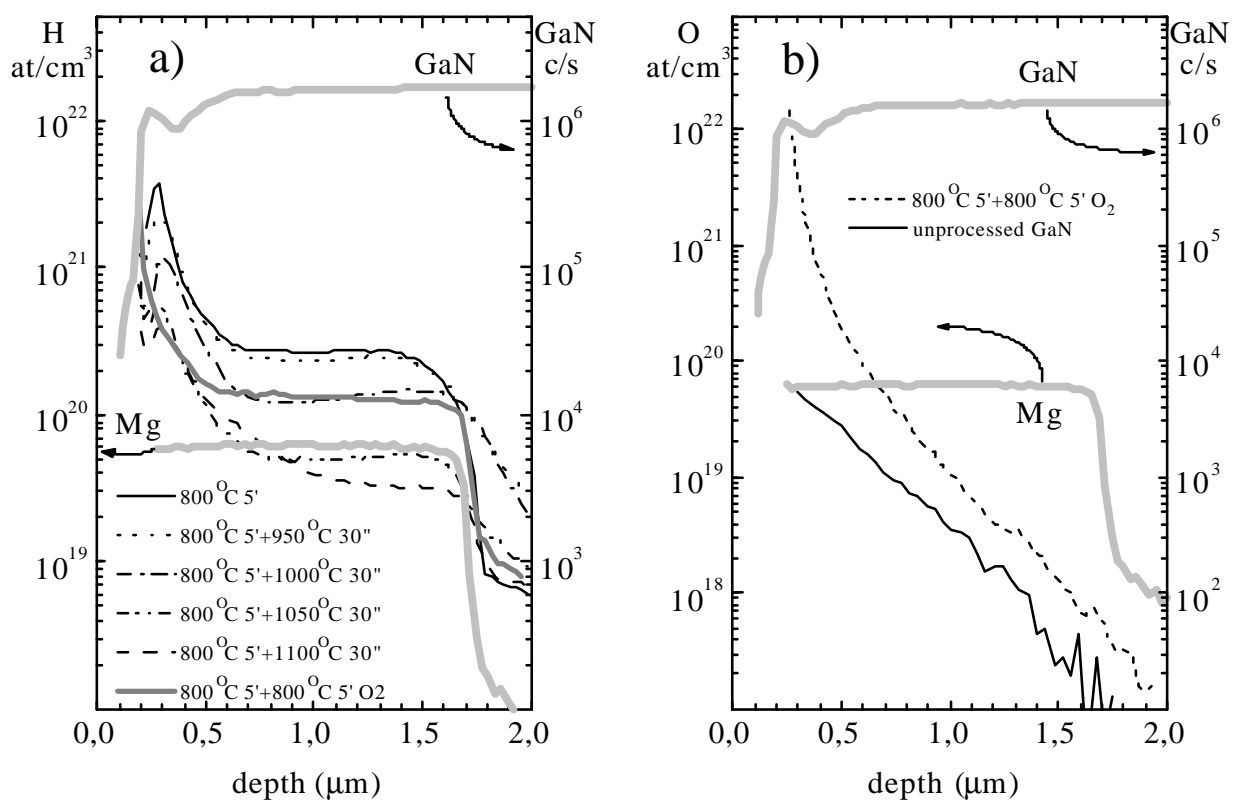

Fig.1. Depth profiles in p-GaN annealed with $\mathrm{ZrN} / \mathrm{ZrB}_{2}$ metallization of a) hydrogen and b) oxygen. 
Concentrations of $\mathrm{H}$ and $\mathrm{Mg}$ in $\mathrm{GaN}$ were evaluated using relative sensitivity factors from ref. [2].

Both $\mathrm{Mg}$ and $\mathrm{H}$ are present throughout the thickness of the $\mathrm{p}-\mathrm{GaN}$ film. The level of $\mathrm{Mg}$ is uniform and remains stable under annealing. In contrast, a substantial accumulation of hydrogen in the subsurface region is clearly seen. The process of hydrogen removal depends on the gas ambient during heat treatment. In $\mathrm{N}_{2}$ atmosphere, it commences at $900-950^{\circ} \mathrm{C}$. After annealing at $\sim 1050^{\circ} \mathrm{C}$ almost all hydrogen from the superficial region and from the bulk of the p-type layer is released. Thermal processing in $\mathrm{O}_{2}$ atmosphere enables to create a hydrogen-depleted subcontact zone at $800^{\circ} \mathrm{C}$.

The release of hydrogen from $\mathrm{p}-\mathrm{GaN}$ has a direct impact on the electrical properties of $\mathrm{p}$ $\mathrm{GaN} / \mathrm{ZrN} / \mathrm{ZrB}_{2}$ contacts. As for contacts processed in $\mathrm{N}_{2}$ ambient, they become low resistive after annealing at $1000^{\circ} \mathrm{C}$ with $\mathrm{r}_{\mathrm{c}}=6-8 \times 10^{5} \Omega \mathrm{cm}^{2}$. Contacts heat treated at $800^{\circ} \mathrm{C}$ in $\mathrm{O}_{2}$ flow were ohmic as well, and exhibited somewhat higher resistivity $r_{c}=1-3 \times 10^{-4} \Omega \mathrm{cm}^{2}$.

As the thermal integrity of the metal/semiconductor system is a key issue in the fabrication of reliable devices, the evolution of $\mathrm{p}-\mathrm{GaN} / \mathrm{ZrN} / \mathrm{ZrB}_{2}$ contact microstructure under annealing was of primary concern. As-deposited metallization is amorphous. Annealing at $800^{\circ} \mathrm{C}$ in $\mathrm{N}_{2}$ causes the recrystallization of both metallic compounds. Fig.2 shows XTEM micrographs and corresponding diffraction patterns of contacts heat treated in $\mathrm{N}_{2}$ and $\mathrm{O}_{2}$ atmospheres, at temperatures required to obtain the ohmic behaviour.
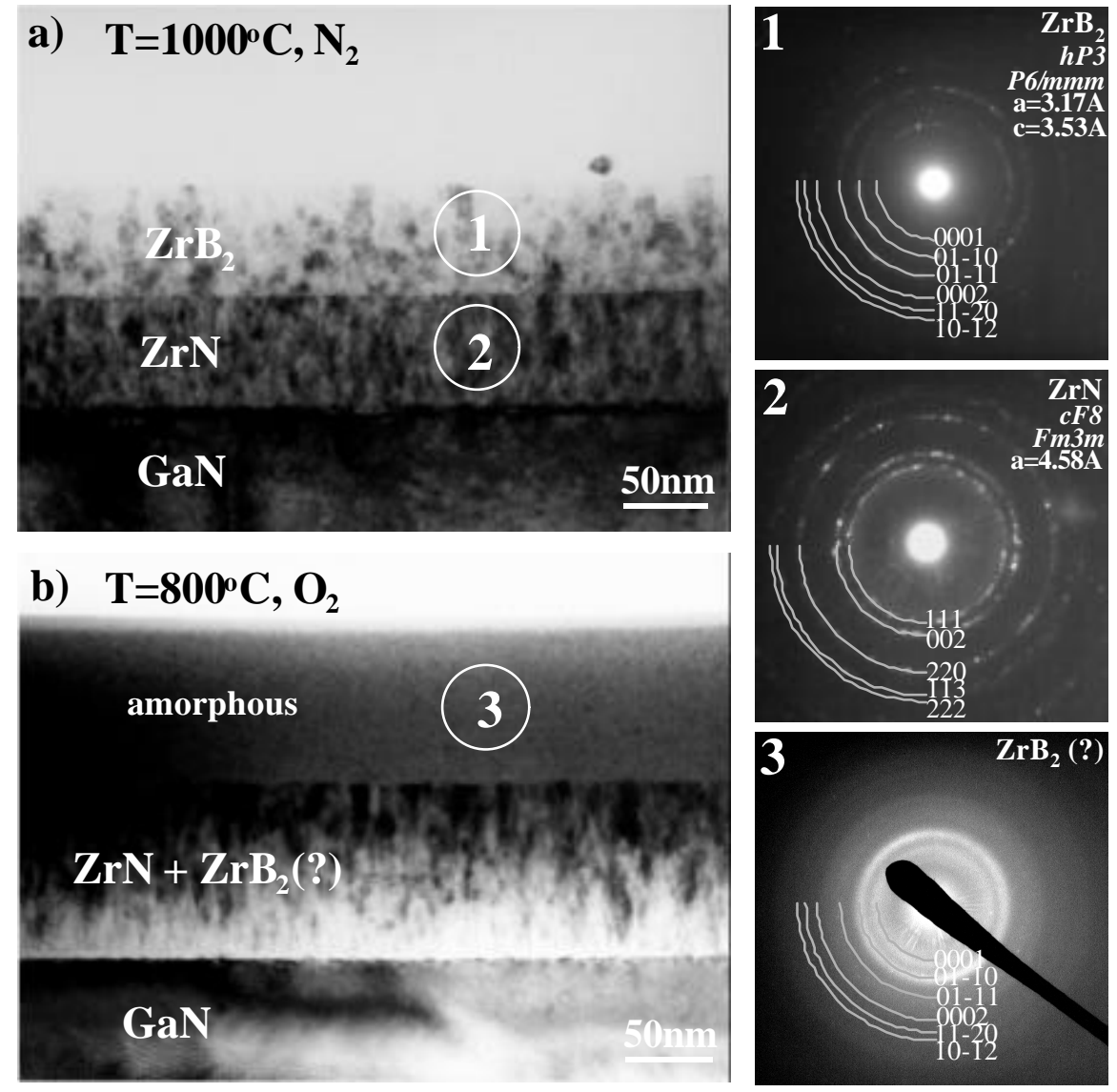

Fig.2. XTEM micrographs and corresponding diffraction patterns of $\mathrm{p}-\mathrm{GaN} / \mathrm{ZrN} / \mathrm{ZrB}_{2}$ contact a) annealed at $1000^{\circ} \mathrm{C}$ in $\mathrm{N}_{2}$ flow, b) annealed at $800^{\circ} \mathrm{C}$ in $\mathrm{O}_{2}$ flow. 
While the metal/semiconductor interface in both contacts is sharp and abrupt, the microstructure of metallization films considerably differs. The final morphology of the contact annealed in $\mathrm{N}_{2}$ is polycrystalline. The metallization is composed of $\mathrm{ZrN}$ and $\mathrm{ZrB}_{2}$ layers, as indicated by SAED ring patterns (Fig2.a). The processing in $\mathrm{O}_{2}$ significantly alters the contact microstructure. The upper part of metallization becomes amorphous. While, SAED pattern of the lower, polycrystalline part revealed mainly the presence of $\mathrm{ZrN}$ (Fig.2.b), SIMS analysis revealed an important intermixing between $\mathrm{ZrN}$ and $\mathrm{ZrB}_{2}$ compounds [3]. To get further insight into the interaction of $\mathrm{O}_{2}$ with the contact, the profile of oxygen in the metallization and in the semiconductor subcontact region has been measured and compared with contact processed in $\mathrm{N}_{2}$. SIMS data evidence an important incorporation of oxygen in the two parts of metallization during annealing. An increase of the oxygen level in the subsurface film of $\mathrm{p}-\mathrm{GaN}$ has been observed, Fig.1.b. The annealing behaviour of $\mathrm{Zr}$-based metallization in $\mathrm{O}_{2}$ atmosphere indicates that such a metallization is not oxidation resistant and does not prevent the diffusion of oxygen into the semiconductor. Taking into account that oxygen is a shallow donor in $\mathrm{GaN}$ [4], when incorporated into the superficial region of $\mathrm{p}-\mathrm{GaN}$ it could compensate freshly activated $\mathrm{Mg}$ acceptor centres. This could be the cause of higher resistivity of contacts processed in $\mathrm{O}_{2}$ as compared to $\mathrm{N}$, in spite of a comparable level of hydrogen in both contacts.

\section{Conclusions}

We have investigated the process of evolution of hydrogen from MOCVD grown $\mathrm{p}-\mathrm{GaN}$ via $\mathrm{Zr}$ based metallization, and determined the optimum processing conditions (temperature and gas ambient) for fabrication of low resistance ohmic contacts. When the process is conducted in $\mathrm{N}_{2}$ flow, the metallization remains stable at temperatures required to achieve the ohmic behaviour, and the morphology of the metal/semiconductor interface is unaltered by such a heat treatment. The processing in $\mathrm{O}_{2}$, on the contrary, causes the interdiffusion of metallization constituents and the incorporation of oxygen into the semiconductor subcontact region, which could be responsible for increased resistivity of these contacts.

\section{Acknowledgements}

This work was partially supported by the Committee for Scientific Research Grant No.PBZ 28.11/P9.

\section{References}

[1] E. Kaminska, A. Piotrowska, A. Barcz, J.Jasinski, M. Zielinski, K.Golaszewska, R.F.Davis, E. Goldys, K. Tomsia, MRS Internet J. Nitride Semicond. Res. 5S1 (2000) W10.9.

[2] J.W. Erikson, Y. Gao, R.G. Wilson, Mat. Res. Soc. Symp. Proc. 395 (1996) 369.

[3] J. Jasinski, E.Kaminska, A. Piotrowska, A. Barcz, M. Zielinski, accepted for publication in MRS Internet J. Nitride Semicond. Res.

[4] C. G. Van de Walle, C. Stampfl, J. Neugebauer, M. D. McCluskey, N.M. Johnson, MRS Internet J. Nitride Semicond. Res. 4S1 (1999) G10.4. 